\title{
A escola em tempos de Covid-19: os estudantes do Colégio Pedro II
}

\section{The school in the days of Covid-19: the students of Colégio Pedro II}

DOI: $10.54019 / \operatorname{sesv3n1-027}$

Recebimento dos originais: 15/01/2022

Aceitação para publicação: 10/02/2022

\section{Liliana Manuela Gaspar Cerveira da Costa \\ NEPEM- Núcleo de Estudos e Pesquisas em Ensino de Matemática; Colégio Pedro II \\ E-mail: Imgccosta@gmail.com}

\author{
Regina Lúcia Faig Torres Pinto da Rocha \\ Colégio Pedro II \\ E-mail: reginaftpr@gmail.com
}

\section{RESUMO}

A presente pesquisa foi desenvolvida no contexto de confinamento social obrigatório, decretado como uma das medidas implementadas no estado do Rio de Janeiro em consequência da pandemia originada pelo Covid19. É uma pesquisa quali-quantitativa, exploratória, de caráter descritivo que recorre a um questionário online para coleta de dados e, assim, se apresenta na forma de um levantamento. Pela sua particularidade, esta pesquisa também se enquadra no que se considera um estudo de caso. Tem como objetivo principal, averiguar qual o impacto do isolamento social obrigatório na sociabilidade e nas interações sociais dos estudantes do Colégio e, em particular, analisar a forma que os estudantes do Colégio Pedro II encontraram para vivenciar o isolamento social obrigatório e indagar quais os seus sentimentos e vivências no período de quarentena. A maioria dos estudantes revelou compreender e apoiar as medidas de isolamento que foram impostas à população, salientando que o bem comum deve ser colocado em primeiro lugar. No entanto, manifestaram desconforto quanto ao momento de incerteza que é vivido, reconhecendo que esse período de quarentena prejudicou suas vidas nos diversos domínios. Saudade, tristeza e ansiedade foram os sentimentos que os estudantes mais referem, destacando-se o papel importante que o colégio e o ambiente escolar desempenham nos seus afetos. Alguns dos questionamentos colocados no início da pesquisa foram completamente respondidos, mas em contrapartida, como consequência de um momento de grande pressão social, em que o stress emocional individual originado pela pandemia trouxe à tona alguns elementos que contribuíram para a ressignificação do papel da instituição escolar junto ao jovem estudante, outros questionamentos e desafios se colocam.

Palavras-chave: escola, isolamento social, cpii, covid-19. 


\section{ABSTRACT}

The present research was developed in the context of mandatory social confinement, enacted as one of the measures implemented in the state of Rio de Janeiro as a result of the pandemic caused by Covid19. It is a qualitativequantitative, exploratory, descriptive research that uses an online questionnaire for data collection and, thus, is presented in the form of a survey. Due to its particularity, this research also fits into what is considered a case study. Its main objective is to investigate the impact of mandatory social isolation on the sociability and social interactions of students at the College and, in particular, to analyze the way that students at Colégio Pedro II found to experience mandatory social isolation and to ask what their feelings and experiences in the period of quarantine. Most students revealed that they understand and support the isolation measures that were imposed on the population, stressing that the common good must be put first. However, they expressed discomfort regarding the moment of uncertainty they are experiencing, recognizing that this period of quarantine has damaged their lives in various domains. Homesickness, sadness and anxiety were the feelings that students most refer to, highlighting the important role that the school and the school environment play in their affections. Some of the questions posed at the beginning of the research were completely answered, but on the other hand, as a consequence of a moment of great social pressure, in which the individual emotional stress caused by the pandemic brought to light some elements that contributed to the resignification of the role of the school institution together with the young student, other questions and challenges arise.

Keywords: school, social isolation, cpii, covid-19.

\section{PREÂMBULO}

O confinamento social obrigatório foi decretado como uma das medidas a implementar no estado do Rio de Janeiro em consequência da pandemia originada pela Covid19. Esse isolamento social, e consequente afastamento da escola, foi vivido pelos estudantes do Colégio Pedro II (CPII) desde 16 de março de 2020. Neste contexto em que, por um motivo alheio à sua vontade, estudantes e professores se viram privados da Escola por um período bastante longo e indefinido, sem o convívio com os seus pares, pareceu ser pertinente questionar de que forma os estudantes do CPII vivenciaram esse afastamento e qual a importância que a instituição e os seus pares desempenharam num momento tão importante de suas vidas.

Assim, a presente pesquisa pretende averiguar qual o impacto do isolamento social obrigatório na sociabilidade e nas interações sociais dos estudantes, bem como, analisar a forma que estes encontraram para o vivenciar. Interessou, também, indagar quais os seus sentimentos e suas vivências no 
período de quarentena, nomeadamente no que diz respeito à sua relação com a instituição escolar. A excepcionalidade da situação vivida faz com que não existam estudos anteriores sobre este assunto no âmbito do CPII.

Trata-se de uma pesquisa quali-quantitativa, exploratória, de caráter descritivo que teve a forma de um levantamento. Pela sua particularidade, uma vez que se visa conhecer como os jovens estudantes de uma dada instituição se comportam em uma situação específica, que é única, esta pesquisa também se enquadra no que se considera um estudo de caso. O estudo é observacional descritivo e os dados coletados e analisados são primários, já que decorrem da aplicação de um questionário original.

A população em estudo é formada pelos estudantes dos Anos Finais do Ensino Fundamental e do Ensino Médio do Colégio Pedro II e a amostra utilizada é constituída pelos estudantes que quiseram participar do estudo e que tiveram permissão para tal.

Em decorrência da impossibilidade de contato entre jovens estudantes e pesquisadoras, optou-se por um questionário online, com 17 perguntas, das quais 4 abertas, 9 fechadas e 4 semiabertas, cujo preenchimento levava, em média, 10 minutos. Algumas perguntas subjetivas, não tinham caráter obrigatório, em decorrência da possibilidade de os jovens estudantes estarem passando por momentos de vulnerabilidade emocional e social, em consequência da pandemia. Algumas perguntas fechadas visavam a caracterização da amostra e as restantes diziam respeito às dimensões sentimentos/emoções, lazeres/sociabilidades, aprendizagens/escola e às suas grandes preocupações. Ressaltando os seguintes aspectos:

$\mathrm{Na}$ obrigatoriedade de ficar em casa em isolamento social, o que o jovem mais gosta e o que menos gosta? O que pensa sobre o fato de não poder ir à escola? Sente a falta da escola nos aspectos relacionados à instituição em si, à aquisição/construção do saber e enquanto espaço das relações sociais? Como está encarando o fato de não ir à escola? Sentirá falta da rotina escolar? Como é que ele e seus amigos se organizaram uma vez que não puderam estar juntos? Encontram-se nas redes sociais? Sentem necessidade de usar outros recursos? Como o jovem ocupa o seu tempo durante este período?

$\mathrm{O}$ instrumento de coleta de dados foi disponibilizado, de junho a agosto de 
2020, através da página web do colégio. Alguns dos campi também disponibilizaram o link de acesso ao questionário nos respectivos blogs e páginas institucionais.

Já na posse das respostas do questionário, procedeu-se à análise quantitativa e qualitativa das mesmas efetuando, quando oportuno, o cruzamento dos dados obtidos, resultados que serão apresentados na seção 4.

Na próxima seção será feita uma descrição sobre a importância e a evolução do papel da Escola segundo as transformações operadas na sociedade e nas relações sociais. Segue-se a seção 3, onde é apresentado o campo da pesquisa: o Colégio Pedro II. Na seção seguinte, como atrás referido, procede-se à análise dos resultados e na última seção são apresentadas algumas conclusões e reflexões.

\section{A IMPORTÂNCIA DA ESCOLA PARA A JUVENTUDE}

As relações entre a juventude e a escola são preocupação de qualquer educador e têm sido objeto de estudo de diferentes pesquisadores. No campo das Ciências Sociais, um dos temas mais relevantes se relaciona ao papel da escola na formação das identidades sociais dos jovens.

As transformações sociais das últimas décadas provocaram alterações significativas nas estruturas sociais, em especial no campo das relações interpessoais e no mundo do trabalho, com consequências para o campo da educação. Como afirmava Castells (1999), essas mudanças reconfiguram diferentes aspectos da vida social. Para os objetivos propostos nesse estudo, uma questão importante é verificar que as novas configurações da vida social têm feito com que a experiência escolar comece cada vez mais cedo, o que ocorre, para boa parte dos estudantes, ainda na primeira infância. Por causa disso, a escola e todas as relações sociais decorrentes dessa inserção passam a ter um papel ainda mais predominante na formação dos indivíduos e na sociabilidade juvenil que se desenvolvem nesse espaço. Portanto, a escola tem de ser analisada como um espaço social "no qual interagem vários atores sociais distintos, com demandas diferenciadas" (LIMA FILHO, 2017, p. 351) 


\subsection{OS SUCESSIVOS PAPEIS DA ESCOLA}

Para Oliveira (2012, p. 90) a escola moderna é uma invenção histórica que "surge com a ascensão do mundo industrial e de uma nova classe social, a burguesia." Neste sentido, a escola vai adquirir três características que seu papel como instituição.

Primeiramente, a escola representa uma nova forma de conceber a formação dos indivíduos e os processos de aprendizagem a ela associados. Em segundo lugar, a escola modifica e transforma "o ensino individualizado em ensino simultâneo para muitos indivíduos" (OLIVEIRA, 2012, p. 90) e ao fazê-lo, insere uma nova organização do processo, que determina novas modalidades de organização do espaço, do tempo e das formas de aquisição e produção de conhecimento. O que interfere na organização da vida social como um todo, desde o mercado de trabalho até as dinâmicas familiares. Por fim, a escola se consolida como instituição pública e passa a ter a função de "produzir cidadãos" (idem, p. 90), o que a torna elemento central na estrutura das sociedades modernas contemporâneas.

A combinação dessas características faz da escola um lugar sui generis e que vai muito além do que está previsto nas propostas hegemônicas de sistema escolar. Dayrell salienta que:

\footnotetext{
(...) a instituição escolar seria o resultado de um confronto de interesses: de um lado uma organização oficial do sistema escolar que define conteúdos da tarefa central, atribui funções, organiza, separa e hierarquiza o espaço (...) definido idealmente, assim, as relações sociais; de outro, os sujeitos - estudantes, professores, funcionários, que criam uma trama própria de interrelações, fazendo da escola um processo permanente de construção social. (DAYRELL, 2001, p. 137)
}

Sacristán (2001) aponta que a obrigatoriedade da educação escolar foi uma criação das sociedades modernas que resume todo um ideal de aspirações de mundo a ser construído pelo capitalismo. Porém essa institucionalização não pode negar as profundas contradições e tensões sociais das sociedades que, em grande medida, são revistas na escola. Como espaço de contradições e tensões, mas também de ressignificação e descobertas, a escola constrói nos sujeitos identidades, pertencimentos e interações que marcam a experiência de vida de cada um e que são determinantes para o posicionamento de cada um de nós na sociedade. 
Duas reflexões são importantes antes de avançarmos na discussão: a primeira, o fato de que a categoria estudante, assim como a de juventude, são construções que se prestam a homogeneizar algo que na prática é bastante diverso e plural e repleto de significados e experiências que não podem ser secundarizadas no debate; a segunda, a constatação de que a experiência escolar dos sujeitos não é unilateral. Na verdade, suas múltiplas relações e vivências fora da escola são trazidas para dentro dela, ainda que as instituições escolares muitas vezes não as reconheçam como relevantes.

Lima (2015, p. 2) afirma que o processo de formação da juventude tem de ser visto como um lugar de disputas "entre diferentes forças que procuram transmitir, através da escola, mas não somente nela, práticas e valores sobre o mundo que permitam o exercício e o controle sobre as ideias produzidas na sociedade." Neste mesmo sentido, Dayrell (2007, p. 1106) frisa a importância da sociabilidade juvenil que se desenvolve na escola, afirma que "a relação da juventude com a escola não se explica em si mesma: o problema não se reduz nem apenas aos jovens, nem apenas à escola, como as análises lineares tendem a conceber." Deste modo, discutir a relação dos jovens com a escola, implica em buscar compreendê-la como resultado de interações entre sujeitos com posicionamentos socioculturais distintos e que no processo produzem novas formas de sociabilidade entre si e com a sociedade e os grupos dos quais participam fora da escola.

As profundas transformações que dão origem à sociedade da informação (CASTELLS, 1999), modificam obviamente o processo de relação dos jovens estudantes com a escola. O emergir de novos processos identitários relacionados aos pertencimentos de classe, raça e gênero indicam novas formas de relacionamento na escola. A difusão das redes sociais online, a dinâmica fugaz dos eventos e das experiências culturais, trazem para o âmbito escolar, questões e dilemas que requerem novas interpretações e propostas.

Como essas novas práticas modificam a sociabilidade no espaço escolar? Se pensarmos a sociabilidade como uma dinâmica de relações que definem os mais próximos e os mais distantes nas quais os estudantes estão profundamente inseridos (DAYRELL, 2007), podemos enxergar a escola como vetor de permanências e novidades. Permanências, na medida em que a trajetória escolar, 
principalmente quando realizada por muitos anos na mesma instituição, tende a consolidar padrões de relações e gerar aproximações e distanciamentos com indivíduos e grupos dentro desse universo. Novidades, na medida em que, como sujeitos em formação e sob a influência de diferentes estímulos sociais, têm seus interesses caracterizados por uma dinâmica que altera os parâmetros que definem o que são próximos e os que são distantes.

Ferreira \& Lima (2011) alertam que uma abordagem das redes sociais online que não considere a estrita relação que elas têm com a realidade material dos estudantes tende a obter resultados pouco efetivos acerca das representações e impactos dessas redes nas relações sociais estabelecidas entre os jovens estudantes.

A sociabilidade dos estudantes está relacionada a outro elemento central nesta pesquisa, a interação. Compreendemos interação como o conjunto de influências recíprocas desenvolvidas por sujeitos em relação. Para Simmel (1983), a interação social ocorre quando os sujeitos criam relações entre si e podem se pautar pela independência ou pela reciprocidade. Nesse sentido, a interação é parte indissociável da presença na escola.

Goffman (2011) entende que a interação social implica em assumir e jogar papeis sociais cujas referências podem ser os pertencimentos anteriores ou aqueles projetados pelos sujeitos para seu presente. Os rituais de interação são típicos também da experiência escolar, na medida em que esses papéis são revistos ao longo do processo de escolarização, principalmente em escolas que possuem diferentes segmentos da educação básica na mesma instituição, caso do Colégio Pedro II, o contexto a que se refere o estudo. O pertencimento à escola cria laços, práticas e formas de compreender o mundo que dependem das relações cotidianas estabelecidas com os demais atores da comunidade escolar.

O sistema escolar brasileiro é bastante diverso. E cada escola pode ser entendida como um lugar que possui ao mesmo tempo, características comuns às demais escolas e elementos que são específicos de cada unidade escolar. $\mathrm{E}$ cada um desses lugares "é um espaço social que contém uma rede de relações dentro de si" (LIMA FILHO, 2017, p.351) que produz nos atores formas de sociabilidade coletivas e particulares. Das peculiaridades deste sistema se destaca o Colégio Pedro II, que será assunto da próxima seção. 


\section{O COLÉGIO PEDRO II (CPII)}

O CPII é uma instituição federal de ensino, equiparada aos institutos federais, com mais de 180 anos de fundação. Atualmente, tem mais do que 12 mil estudantes, dos quais, cerca de 9 mil são do Ensino Fundamental II (EFII) e do Ensino Médio (EM), regular e Integrado e é constituído por 15 campi.

O CPII é considerado uma instituição de vanguarda no que se refere a práticas pedagógicas inovadoras e onde são respeitados os princípios preconizados nos documentos oficiais nacionais, no que concerne ao respeito pela diversidade e a uma formação integral dos estudantes, e que tem como objetivo final a formação de cidadãos responsáveis, autônomos, críticos e solidários.

A história do Colégio se entrelaça com a da educação nacional e com o desenvolvimento científico, tecnológico, artístico, cultural e político do Brasil. As transformações ocorridas no CPII nos anos 2000 não modificaram somente seu tamanho ou reafirmaram a sua importância histórica para a educação brasileira. A partir da inserção de diferentes sujeitos, muitos deles pertencentes a grupos sociais que antes tinham pouca ou nenhuma presença no cotidiano escolar, elas também produziram um novo espaço social.

A expansão da instituição para regiões periféricas da cidade do Rio de Janeiro, e municípios vizinhos, ampliou a representação de negras e negros entre os estudantes, aumentou exponencialmente o número de alunas e estudantes matriculados, mas principalmente povoou o ambiente escolar de uma rica diversidade, o que influencia diretamente nas relações sociais estabelecidas dentro dos diversos campi da escola. A escola torna-se assim, um espaço de experiências singulares dadas pelos processos presenciais de interação entre os diferentes sujeitos.

Paralelamente, não há como desconsiderar as diferenças econômicas, culturais e políticas que esse novo contexto revela. Há estudantes que têm carências materiais severas, outras e outros que pouco conhecem dos espaços além do trajeto casa/colégio. Desse modo, a vivência do dia a dia da escola permite formas de interação que o afastamento social pode dificultar.

Num momento de grande pressão social, o stress emocional individual originado pela pandemia será capaz de trazer à tona alguns elementos que 
poderão contribuir para a ressignificação do papel da instituição escolar junto ao jovem estudante. Dayrell (1996, p. 137) ressalta que "o processo educativo escolar recoloca a cada instante a reprodução do velho e a possibilidade da construção do novo, e nenhum dos lados pode antecipar uma vitória completa e definitiva".

\subsection{ALGUNS QUESTIONAMENTOS}

Os processos de interação mudaram em decorrência do longo período de afastamento da escola, e, consequentemente, as relações entre os diversos sujeitos e destes com a instituição. Averiguar qual o impacto provocado e de que modo o afastamento pode afetar as vivências dos estudantes é muito importante para se poder entender o papel da escola para os estudantes do CPII. Ainda, de acordo com Dayrell (1996, p. 137), ao buscar apreender processos reais e cotidianos que ocorrem no interior da instituição, a análise educacional será ampliada e, simultaneamente, o papel ativo dos estudantes na participação da vida social e escolar será resgatado.

As relações que se estabelecem não se limitam assim ao espaço escolar; elas perpassam a vida social do estudante. Segundo Dayrell (1996), observa-se no dia a dia "uma complexa rede de relações entre os sujeitos que fazem parte da mesma e que incluem "alianças e conflitos, imposição de normas e estratégias individuais, ou coletivas, de transgressão e de acordos". Constata-se:

\footnotetext{
Um processo de apropriação constante dos espaços, das normas, das práticas e dos saberes que dão forma à vida escolar. Fruto da ação recíproca entre o sujeito e a instituição, esse processo, como tal, é heterogêneo. Nessa perspectiva, a realidade escolar aparece mediada, no cotidiano, pela apropriação, elaboração, reelaboração ou repulsa expressas pelos sujeitos sociais (Ezpeleta \& Rockwell1986). (DAYRELL, 1996, p.137)
}

Se essas relações são parte da construção dos jovens estudantes, num momento em que esses e outros atores se viram afastados do colégio por conta das medidas adotadas pela pandemia da COVID 19, torna-se pertinente questionar de que forma eles encaram esse afastamento e qual a importância que a instituição e os seus pares desempenham nesse momento singular de suas vidas. Algumas questões que buscámos problematizar nesta pesquisa e cujas respostas poderão emanar (ou não) da análise dos dados coletados: 
Qual a visão que o jovem estudante do CPII possui sobre a sua vivência escolar? Qual a importância e significados que ele atribui à escola? Qual a importância que o jovem estudante do CPII atribui ao seu grupo de convívio escolar? Qual a sua capacidade de reagir à adversidade?

\section{O QUE PENSAM/SENTEM OS ESTUDANTES DO CPII?}

\subsection{Quem Aderiu? Quem Participou? Quem Respondeu?}

No universo de cerca de 9 mil estudantes do $6^{\circ}$ ano do EF ao $3^{\circ}$ ano do EM, somente 845 acessaram ao questionário. No entanto, destes, apenas 266 estudantes, cerca de 31\%, responderam integralmente ao mesmo. Do número de respostas completas, os maiores percentuais se concentraram em dois campi, $\mathrm{C}$ e EN II ${ }^{1}$, com cerca de $34 \%$ e $29 \%$ das respostas (Figura 1), respectivamente.

Figura 1 - Distribuição das respostas por Campus

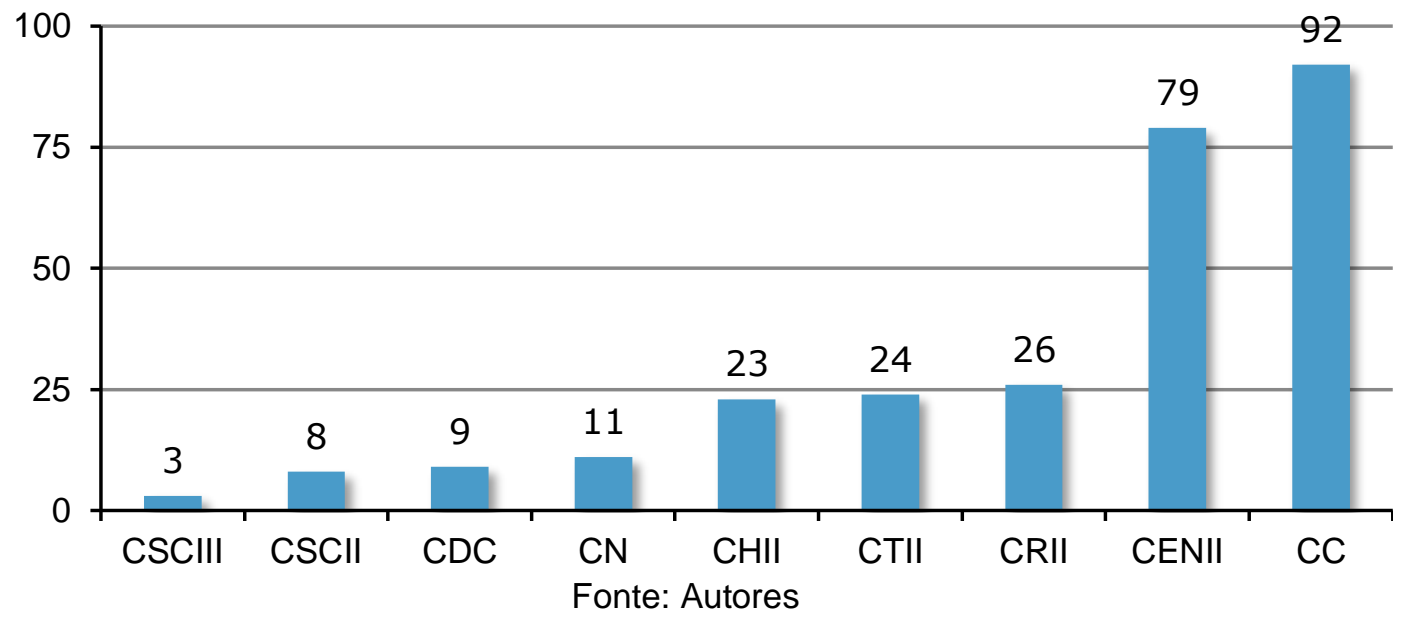

Quanto à raça e sexo, a amostra segue a tendência dos dados gerais do CPII. No entanto, há um aumento significativo do percentual do número de meninas, o que leva a perguntar se estas são mais atuantes em relação a este tipo de problemática do que os rapazes.

Sobre a zona de residência, os dados refletem o fato de as respostas ao questionário terem sido maioritariamente de estudantes dos campi C e EN II, destacando-se, assim, a Zona Norte com cerca de 61\%, seguida das Zona Oeste

\footnotetext{
${ }^{1}$ Os nomes dos Campi são: Campus São Cristóvão III (CSCIII), Campus São Cristóvão II (CSCII), Campus Duque de Caxias (CDC), Campus Niterói (CN), Campus Humaitá II(CHII), Campus Tijuca II (CTII), Campus Realengo II (CRII), Campus Engenho Novo II (CENII) e Campus Centro (CC).
} 
e Zona Sul com cerca de $14 \%$ e $10 \%$, respetivamente.

É interessante notar que os estudantes dos dois anos de escolaridade em que há ingresso na instituição foram os que mais aderiram à pesquisa. Os estudantes do $6^{\circ}$ ano $E F$, com cerca de $24 \%$ das respostas, foram os que mais participaram, seguidos dos estudantes do $1^{\circ}$ ano do EM com cerca de $16 \%$ das respostas.

\subsection{AGORA TUDO É DIFERENTE}

Os estudantes foram indagados acerca das impressões sobre a quarentena obrigatória em relação ao isolamento social, ao afastamento do convívio dos e das colegas, à impossibilidade de ir à escola e à suspensão temporária das atividades de aprendizagem escolar. Apesar de um grupo significativo de estudantes manifestar o seu desagrado em relação à quarentena obrigatória e consequente isolamento social, a necessidade e importância da medida é reconhecida pela grande maioria dos estudantes, incluindo muitos daqueles que a consideram desagradável.

É muito necessário para que o vírus não seja disseminado para mais pessoas, porém deixa um vazio muito grande nas nossas vidas. Ir à escola, sair de casa e ter contato com os amigos era uma coisa muito normal e agora tudo é diferente. Não é fácil lidar com essas mudanças, mesmo que necessárias para combater o vírus. ( $\mathrm{m}, 1^{\circ}$ ano EM, CN)

O reconhecimento da importância de cada um ficar em sua casa é acompanhado da manifestação de vários sentimentos contraditórios que vão desde a saudade e tristeza, ao medo e frustração. No entanto, nem todos os estudantes se pronunciaram sobre este tópico.

A quarentena é necessária, mas há também a ansiedade que nos afronta ao pensarmos na suspensão das aulas e na possibilidade de suspensão do ano letivo. Mantenho o contato com meus colegas pela Internet, mas sinto falta do contato físico com eles e com a escola. (m) , 3o ano EM, CRII)

\subsection{SAUDADES / TRISTEZA / ANSIEDADE}

Os estudantes escreveram três palavras em ordem de importância para expressar seus sentimentos por estarem afastados da escola. Para expor as informações coletadas utilizaram-se nuvens de palavras (Figura 2). Comparando as duas primeiras nuvens, nota-se que saudade do colégio é o sentimento 
preponderante, seguido por frustração, ansiedade, tédio, incerteza, medo e insegurança. Na terceira nuvem, destacam-se, também, tristeza, preocupação, solidão e preguiça.

Representando todas as palavras numa única nuvem, contabiliza-se a incidência da seguinte forma: saudades (129), tristeza (91), ansiedade (71), medo (42), preocupação (39). Cerca de metade dos estudantes manifestou sentir saudade do colégio, revelando o papel que este desempenha nos seus afetos.

Figura 2 - Expressão dos sentimentos por estar afastado da escola.
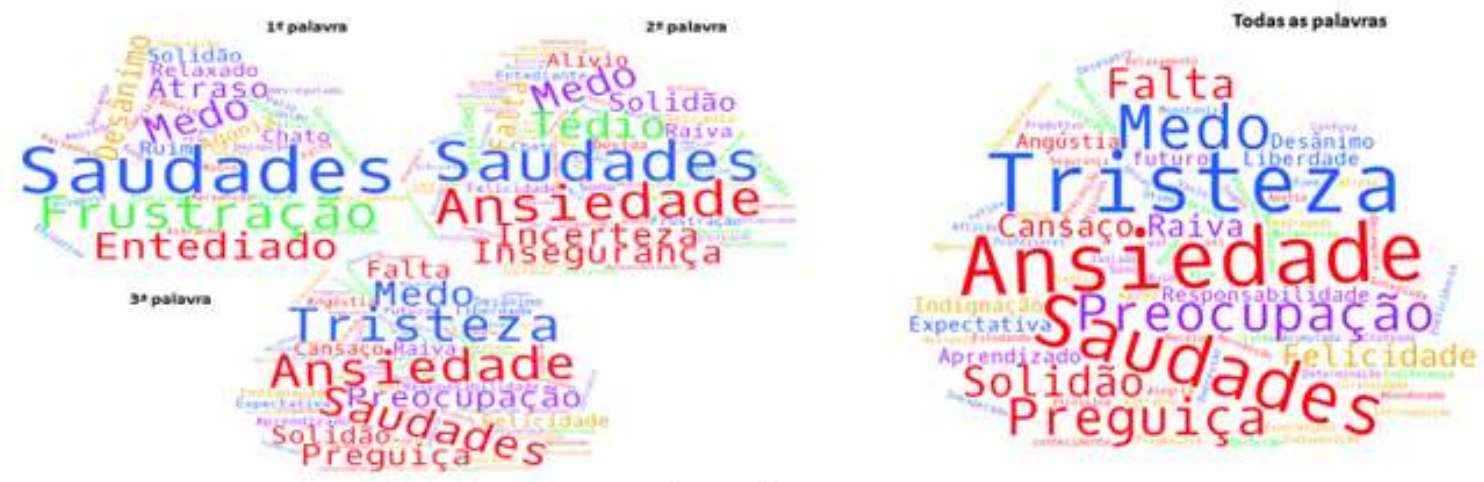

Fonte: Autores

Verifica-se, também, que a experiência do afastamento de parentes e amigos impactou de forma considerável a vida desses jovens estudantes, como podemos observar em alguns dos relatos recolhidos como alguns dos problemas que mais os afetaram:

- Alguns dos meus parentes estão deprimidos e com medo de sair, eu não visito meus parentes com tanta frequência, às vezes, me pego triste e desanimada. , 9 ano EF, CENII)

- Me afastar das pessoas que gosto, não poder sair para passear e viver com um medo constante sempre limpando tudo e lavando as mãos a todo momento. ( $>$, $8^{\circ}$ ano $\mathrm{EF}, \mathrm{CC}$ )

- O problema maior é a falta de socialização, estar a mais de 3 meses sem ter contato intenso com os meus amigos, realmente me causa danos. ( $A 9^{9}$ ano EF, CENII)

Os problemas emocionais que aparecem referidos em algumas respostas dos estudantes são acompanhados por relatos de instabilidade emocional, depressão, tristeza e desânimo, como os reproduzidos abaixo: 
- O segundo problema que mais afeta é a ansiedade de saber como vai ficar o futuro, sem saber se alguém próximo vai morrer ou como vai ser comigo tendo que me formar apenas aos 20 anos, perdendo mais um ano da minha vida com a quarentena basicamente, a única coisa que nos preocupa nesse cenário é nossa saúde psicológica. ( C) , 3ano EM, CRII)

- Problema emocional, pois nunca passamos por nada parecido e a quantidade de informações desencontradas era mais desesperador.

(C), $3^{\circ}$ ano EM, CRII)

A carga emocional relatada pelos estudantes do Colégio Pedro II em decorrência das mudanças de rotina, dos medos, dos problemas socioemocionais e econômicos, chama a atenção das pesquisadoras, pois a partir dos dados coletados constata-se que a saúde mental é um dos pontos de maior preocupação para os estudantes da instituição.

\subsection{NÃO PODER SAIR DE CASA, O ESTADO DE ANSIEDADE E A VIDA TER PARADO}

As grandes preocupações referidas pelos estudantes em relação ao presente e ao futuro foram em primeiro lugar, as questões financeiras, que atingiram muitas famílias em maior ou menor escala. Perda de renda e desemprego surgem como preocupações em relação à vida familiar e, também, em relação ao colégio. No entanto, no computo geral foi o afastamento de parentes e amigos que se revelou ser o principal problema decorrente da pandemia, seguido da falta de aulas.

O que me preocupa na minha vida familiar é a possibilidade de ficar
muito doente ou alguém da minha família, a possibilidade de ficarem sem
dinheiro para se sustentarem e também a saudade que sentimos uns
dos outros. Em relação aos meus estudos o que me preocupa é
possibilidade de ficarmos muito atrasados em relação ao ano letivo de
outras escolas. Em relação ao meu colégio o que me preocupa é a falta
de verbas, que pode acarretar diversos problemas e os diversos ataques
que o colégio tem recebido. (

Como em outros momentos, houve, também, grande incidência na referência a problemas de natureza psicoemocional, tais como: depressão, tédio, tristeza, desânimo, estresse, frustração, desmotivação, angústia e ansiedade e, também, a falta de atividades escolares. Um tópico importante foi, mais uma vez, a referência explícita por um número considerável de estudantes à preocupação com as suas condições de saúde mental e ao estado de desânimo que viviam. 
A maior preocupação que eu tenho é referente a saúde dos meus familiares, principalmente os mais velhos. Confesso que estou muito preocupado com a procedência do ano letivo, não sei se seria melhor continuar em 2020, por mais que o colégio aperte tudo(o que é extremamente prejudicial para o estudante) ou cancelar o Ano letivo. Tenho algumas preocupações relacionadas ao meu lado emocional, que tenta encontrar novos ânimos nessa quarentena, mas nem sempre consegue. ( 9 , $1^{\circ}$ ano $\mathrm{EM}, \mathrm{CC}$ )

Quando perguntados sobre as preocupações em relação ao futuro, os estudantes mostraram-se receosos quanto ao destino de suas vidas, à cura da doença, ao retorno à vida normal e à retomada das atividades escolares.

\begin{abstract}
Meu maior medo é, não ter energia e capacidade psicologica de voltar a rotina como antes, não conseguir voltar a conhecer e ter uma relação boa com os colegas novos. Não ser capaz de estudar como antes. Ter o ano "bagunçado" por conta da volta às aulas (por exemplo voltar o ano letivo em setembro). Tenho preocupação também se a escola adotará o EAD, que não tem se mostrado muito eficaz. Queria poder ter acesso a aulas presenciais quando for seguro. ( 60 ano EF, CC)
\end{abstract}

Medo do vírus, falta de perspectiva de vacina a curto prazo, nova onda de contágio, sonhos adiados foram algumas das preocupações com o futuro. Há um desejo enorme de voltar à normalidade, de não ter medo de se aproximar das pessoas e retomar o contato próximo e despreocupado. As respostas quanto às preocupações do presente se misturaram com as projetadas para o futuro. Há algumas respostas relativas às expectativas sobre o futuro em que foi possível observar a reflexão sobre o atual momento, numa perspectiva esperançosa, como está patente em alguns dos trechos a seguir:

- O que mais me preocupa agora é saber quando isso tudo vai acabar, quando iremos poder voltar a viver normalmente e seguir nossas rotinas, em geral estou preocupada sobre o futuro e o que ele pode reservar.

( Q , 7ํano EF, CENII)

- Como nos comportaremos frente a esse novo mundo. Será que daremos mais atenção ao próximo, a natureza, a sua família e amigos? Quando poderemos abraçar quem amamos? Será que a cura está próxima? Aprendemos a amar o próximo? ( 8 8ano EF, CENII)

Uma das grandes preocupações manifestada por uma parte significativa dos estudantes, relativamente aos estudos, é que as aulas regressem apenas em 2021 e isso acarretar a perda do ano letivo. 


\subsection{SINTO FALTA DO APRENDIZADO E DAS AMIZADES}

A falta de aulas presenciais ou remotas foi um dos problemas mais referidos pelos estudantes que, apesar de se terem posicionado favoráveis às medidas adotadas pelo Colégio quanto às atividades educativas remotas, também manifestaram preocupação com as possíveis consequências. Cerca de metade dos estudantes, se ressentem por não ter atividades escolares, ainda que remotas, pois temem possíveis perdas na aprendizagem.

A relação do jovem estudante com a escola se modifica durante a pandemia, pois a ausência de aulas presenciais traz novas ressignificações do espaço escolar. Há o desejo de estar nesse ambiente, de encontros, de trocas e aprendizagens e a imposição do isolamento os afeta no âmbito social, emocional e educacional.

Em relação à vida escolar, os estudantes mostram-se apreensivos com a possibilidade de perder o ano e/ou atrasar os estudos e com a perda de rotina associada à escola.

Uma questão que intrigava as pesquisadoras dizia respeito ao posicionamento que os estudantes teriam relativamente ao ensino remoto e atividades online, já que o colégio, considerando que nem todos os estudantes teriam condições de acesso à Internet, entendeu não disponibilizar atividades online. Ora, o número de estudantes que referiu dever ter havido aulas à distância não se mostrou significativo e mesmo alguns destes disseram concordar com a opção do colégio.

Cerca de 75 dos estudantes que responderam ao questionário refere explicitamente sentir falta da escola, dos professores e do convívio com os colegas.

- A quarentena é obrigatória tendo em vista que precisamos nos distanciar para o vírus não se propagar. Mas, de certa forma, é horrível. Pois não temos o que fazer em casa e ficamos com MI ITTA saudade do colégio que é como se fosse nossa segunda casa. ( $72^{\circ}$ ano EM CTII)

- $\quad$ Eu sinto falta dos meus amigos, de brincar com eles etc, sinto falta dos professores, da minha escola. Sinto falta das coisas comuns do dia a dia.

(ca) , 8a ano EF, CC)

Vários estudantes manifestaram sentir a falta do apoio dos professores, nomeadamente sentir a necessidade da sua presença para o aprendizado ser 
eficaz.

- $\quad$ Para mim está sendo horrível, o afastamento do convívio nem muda tanto devido a ferramentas de mensagens como WhatsApp etc. Porém o afastamento das atividades me afeta bastante devido ao ano que estou $\left(3^{\circ}\right)$ e pelo fato de que eu nunca consegui aprender por mim mesmo, sempre precisei de professores e aulas presenciais para poder aprender. ( $33^{\circ}$ ano EM, CENII)

- $\quad$ O isolamento é meio angustiante mas é importante, em relação ao afastamento nós estamos msm afastados ainda mais unidos, eu sinto muita a falta da escola do convívio dos professores. $\mathrm{CHII)}$

(.) $9^{\circ}$ ano $\mathrm{EF}$,

Mas, a indefinição e falta de informação foram consideradas como elementos perturbadores e em várias respostas é patente uma mágoa em relação à escola no que concerne à deficiente comunicação entre a instituição e os estudantes.

Acredito que a escola poderia reorganizar o meio de envio dos trabalhos de casa, porque acaba ficando um pouco confuso nessa parte. Algumas vezes me são enviadas algumas tarefas por e-mail mas ainda sim, seria melhor se o colégio adotasse uma rotina de envio pelo menos. Sei que a situação está complicada para todos, mas é por isso mesmo que há de ter mobilizacão da parte da escola. Fora isso, tudo segue conforme o esperado.(@, $7^{\circ}$ ano EF, CC)

Os estudantes sentem muita falta do colégio. A maioria tem uma opinião negativa sobre o fato de não poder ir ao colégio, sendo que cerca de $47 \%$ consideram ser péssimo não ir à escola e cerca de $28 \%$ ruim (Figura 3). Mas, há bastantes estudantes que se mostraram indiferentes a essa situação. Independentemente do seu sentir individual, nas justificativas, os estudantes tiveram uma postura crítica, apontando para a urgência do momento em que a sociedade vive, no qual a pandemia não foi controlada. 
Figura 3 - O que os estudantes pensam sobre não ir à escola

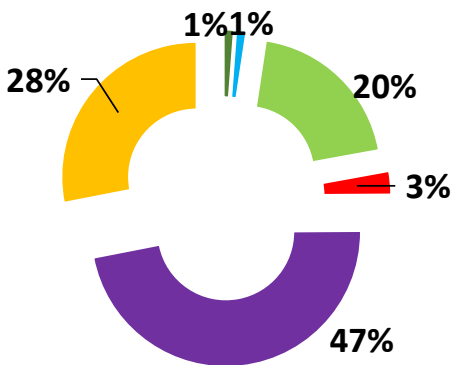

Bom

Não quero opinar

Nem bom nem ruim

- Ótimo

- Péssimo

Fonte: Autores

Os estudantes se manifestaram seguindo alguns critérios de análise da situação, 3\% manifestaram ser "ótimo" não ir à escola:

- Por estarmos em uma pandemia, não acho inteligente circularmos nas ruas. ( 1 1ำ ano EM, CTII)

- Não me sentiria segura em ir à escola nesse momento. (C), $8^{\mathrm{a}}$ ano $\mathrm{EF}, \mathrm{CC})$

No outro extremo da escala, $47 \%$ julgaram ser "péssimo":

- Eu não consigo estudar sem o auxílio dos professores, isso é péssimo! ( 3 , 2ano EM, CN)

- A escola é essencial em nossas vidas e até mesmo no convívio com outras pessoas. ( $2^{\circ}$ ano EM, CRII)

- Eu gosto de estar na escola, o ambiente escolar que participo é leve e eu gosto de estar lá, gosto de aprender, gosto de chegar em casa e contar algo novo que algum professor me ensinou, gosto dos meus professores e gosto dos meus colegas de classe, por isso é ruim.

( .2 , 2ano EM, CTII)

Numa escala ascendente de valores, $28 \%$ julgaram ser "ruim":

- Não poder ir à escola é uma medida de segurança importante de ser tomada e seguida, mas é muito ruim o sentimento de "ficar para trás".

(A) $1^{\circ}$ ano EM, CN)

- É ruim porque, para mim, é mais complicado de estudar em casa, não tenho um incentivo ou obrigação, não sinto vontade e automaticamente fico mal por não conseguir estudar em casa. Só que nesse período precisamos dessa medida. 3ano EM, CRII)

E, finalmente, $20 \%$ acharam "nem bom nem ruim":

- Ruim por ter de viver à base do EAD e bom por ter medidas que de combate ao vírus e nem bom nem ruim por equilíbrio entre não poder 
estudar - presencialmente - e reduzir o risco de contágio; porém, prefiro pontuar ruim, pois necessitamos da escola. ( A 3 3ano EM, CSCIII)

- Por um lado, é bom para evitar o contágio e proliferação da Covid-19, mas é ruim pois estamos com os estudos parados, atrasando nosso ano letivo e nossos planos. , 2ano EM, CENII )

Em que grau a falta da escola é sentida pelos estudantes? Cerca de $90 \%$ dizem sentir falta da escola, (Figura 4), sendo que $61 \%$ dizem sentir muita falta e $28 \%$ sentem falta num grau médio.

Figura 4 - Você sente a falta da escola?

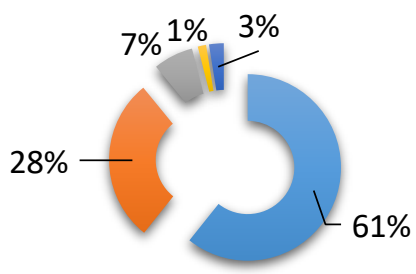

Muito
Médio
Pouco
Nada
Não quero opinar

Fonte: Autoras

Mas será que todos os estudantes sentem a falta do colégio da mesma forma, ou haverá uma diferença significativa nos motivos que estão na origem desse sentir? Neste sentido, foi fornecida aos estudantes, uma lista de aspectos para serem selecionados (Figura 5). Dentre estes, sentir falta do convívio com os colegas foi destacado por quase todos, mas os aspectos relacionados com a rotina de atividades diárias e as aulas dos professores são também escolhidos por um número significativo de estudantes, seguindo-se as brincadeiras e diversões com os colegas, o ambiente constante de aprendizagem e orientação para o estudo. Dois aspectos merecem especial destaque: por um lado, cerca de $44 \%$ dos estudantes referem sentir falta do uso do uniforme do colégio e, por outro, cerca de $22 \%$ dos estudantes dizem sentir falta das refeições do refeitório do colégio. A falta do uso do uniforme poderá estar relacionada com a questão da identificação e pertencimento à instituição, enquanto a falta do refeitório poderá estar relacionada aos problemas sociais de baixa renda, sendo que é sabido que a refeição principal de alguns estudantes é feita na escola. 
Figura 5: Do que sentem saudade no colégio?

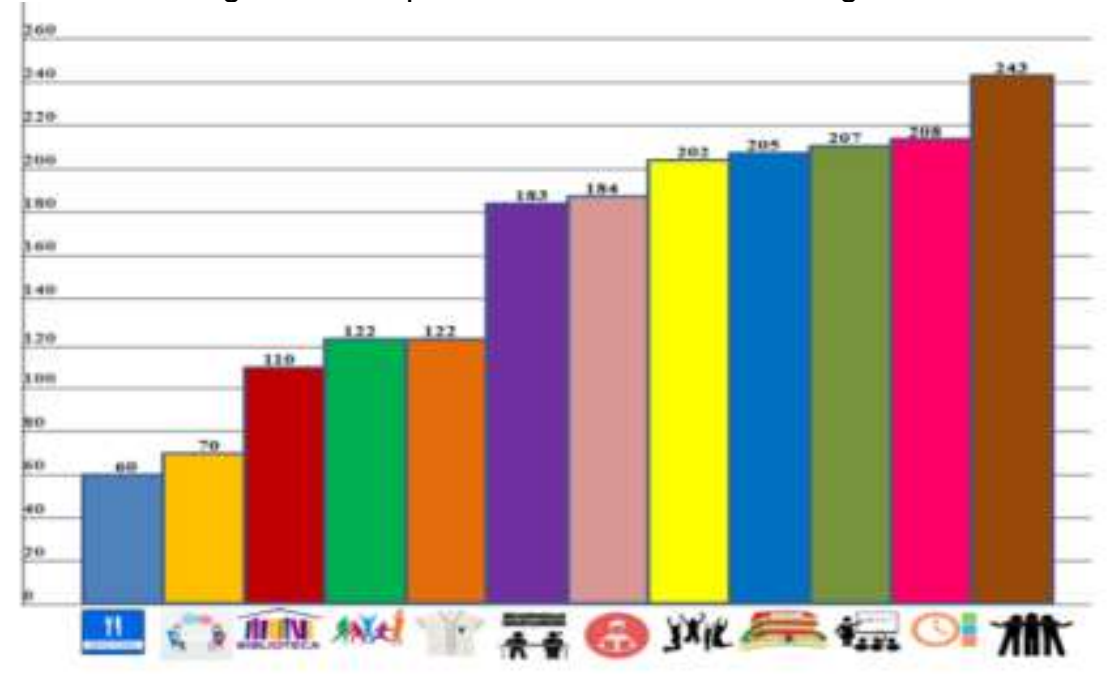

il Refeiçōes do refeitório do colégio

Presença de um profissional do colégio para conversar

\section{Biblioteca}

Ality Atividades esportivas

Usar o uniforme do colegio

1. का

Orientação para os meus estudos

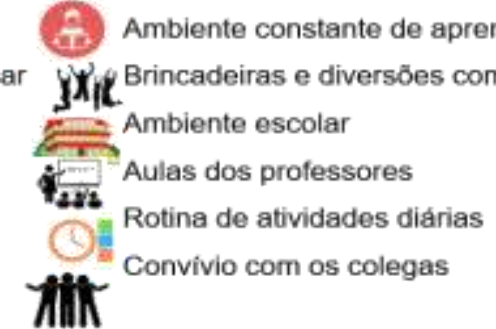

Fonte: Autores

\subsection{CONSUMO CULTURAL DIGITAL}

E como os nossos estudantes ocuparam o seu tempo durante o período da pandemia? As atividades de lazer e convívio no âmbito da comunicação digital, tais como ouvir música, jogar jogos eletrônicos, ver filmes e séries por streaming e TV, bem como interagir nas redes sociais são aquelas que os estudantes expressaram preferir para ocupar o tempo durante a pandemia. Atividades tais como, acessar conteúdos no Youtube, ver séries/filmes, ouvir música, jogar videogame/ jogos no celular são as que se destacam, seguidas de conversar com parentes e amigos pelas redes sociais. Só depois surgem as atividades referentes à colaboração com o núcleo familiar. A situação pandêmica acentuou ainda mais a cultura do digital, na qual as relações se estabelecem de forma online, contrapondo a esta situação o fato muitos jovens sentirem a falta dos espaços presenciais e das relações de proximidade com seus pares. Outro aspecto que merece destaque é o baixo percentual de estudante que destinaram o tempo ao estudo através de aulas no Youtube ou de outro canal, pesquisa de assuntos escolares na Internet ou mesmo revisar matérias anteriores ao período de isolamento. Em contraponto, a leitura surge como a atividade que os estudantes 
menos gostam de realizar, o que pode levar a concluir que a leitura é feita por obrigação apenas no ato de estudar. Ler e estudar são atividades que apenas mobilizam menos de metade dos estudantes.

Um aspecto preocupante é o fato de apenas $40 \%$ dos jovens manifestarem a prática de exercício físico durante este período, o que poderá ter consequência ao nível de saúde.

No que concerne às preferências dos jovens para comunicarem entre si, as hipóteses das pesquisadoras foram confirmadas. Apenas 10\% dos estudantes referem que não usam as redes sociais para comunicar com os amigos. Dos restantes $90 \%$, a maioria prefere o contato através do chat e de encontros de vídeo de diversos aplicativos de celular (Figura 6). A comunicação também foi feita visando a parte lúdica, nomeadamente relativa a permutas de jogos online, atividade que é, também, bastante popular entre os estudantes.

Figura 6 - Como você se organiza para se comunicar e conviver com seus amigos?

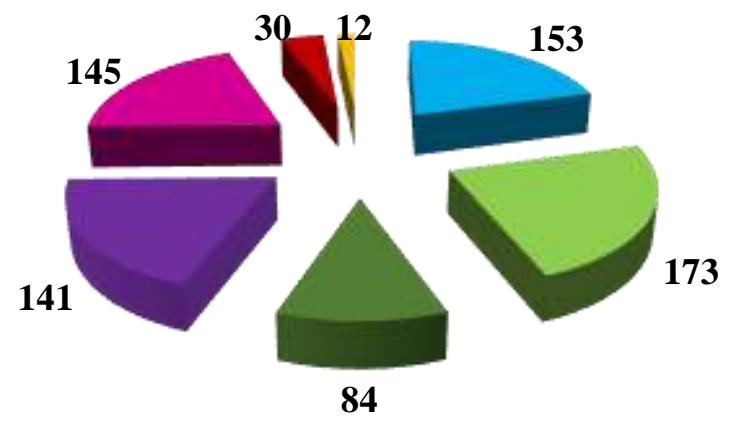
- Encontros através de vídeos por aplicativos de celular
- Conversa por chat
- Conversa por celular/ SMS
- Fala por telefone/celular
- Partilha jogos online por celular e/ou computador
- Não se encontra online com os amigos
Outro (especifique)

Fonte: Autoras

\section{CONSIDERAÇÕES FINAIS}

Diante do cenário da pandemia, a pesquisa buscou entender como o afastamento foi sentido pelos estudantes no que concerne às suas preocupações, anseios e expectativas tanto no que tange às relações familiares, interpessoais e com a escola e, também, investigar a forma como viveram esse período de isolamento.

O primeiro grande desafio consistiu em alcançar o maior percentual de participação dos estudantes na pesquisa. À priori, acreditava-se que o percentual de respostas seria maior do que o registrado. O que esteve na origem de, apenas, cerca de $10 \%$ dos estudantes do CPII terem tido interesse em acessar ao questionário? As hipóteses para tal quantitativo podem estar relacionadas com a 
dificuldade de comunicação de alguns campi com os estudantes e seus responsáveis, com o acesso precário aos blogs e web página institucional e, também, ao fato de algumas famílias (cujo número não é conhecido) terem acesso precário ou não terem acesso à Internet e ser este ser o canal de comunicação com os estudantes.

Apesar dos entraves existentes, cerca de 61\% das respostas dos estudantes expressaram compreensão e apoio às medidas de isolamento que foram impostas à população, por entenderem a gravidade dos fatos e revelarem ter a consciência de que esta era a melhor/única opção que poderia ter sido tomada tendo em vista o bem comum. Contudo, relataram diversas aflições quanto ao rumo de suas vidas e aos consequentes afastamentos a que foram obrigados. Inegavelmente, entenderam que esse período de quarentena prejudicou suas vidas no âmbito pessoal, social e educacional.

Saudade, tristeza e ansiedade foram os sentimentos que mais marcaram os estudantes durante esse período. Quantos sonhos adiados, o temor da doença, a preocupação com a sua saúde mental e a falta de perspectivas quanto ao futuro estiveram presentes nos seus relatos. A comunicação entre os jovens estudantes e a forma utilizada para a partilha de suas ideias, experiências e angústias confirmou a relevância das redes sociais digitais cuja presença contribuiu para amenizar as consequências da ausência de convívio social. Os estudantes utilizaram chats, encontros por vídeo e partilharam jogos online, como o meio para conviver e interagir. Observa-se que a situação pandêmica acentuou ainda mais a cultura do digital, mostrando-se como recurso fundamental para manter conexão mínima entre os membros de uma geração que já nasceu conectada.

Das atividades que os estudantes relataram preferir fazer durante a pandemia, há algumas que eles referiram gostar e que fizeram muito. No entanto, há tarefas que salientam não gostar de fazer, mas que fizeram. Resta saber se tal aconteceu por iniciativa própria, ou por serem obrigados ou por julgarem sua execução ser importante. Por exemplo, "ler livros" é uma das atividades que surge com menor indicador de preferência, mas os estudantes referem que é uma das atividades com a qual ocupam o seu tempo. Esta constatação a nível da pesquisa no âmbito do CPII, nos remete a diversas reflexões sobre a importância de credibilizar com veemência a prática de leitura. A pesquisa reforça, ainda mais, 
nossas convicções e nossas práticas no CPII, quanto ao incentivo e ao fomento da prática da leitura.

Se a priori, existia o questionamento sobre o tipo de relação dos estudantes com o colégio nos períodos antes e durante a pandemia e de procurar entender essa mesma relação. Há, neste momento, uma nova discussão, as escolas fecharam as portas e os estudantes se depararam com uma situação diversa, na qual não podem ocupar o espaço escolar, não podem firmar suas relações e significar esse ambiente social. Sendo a escola um espaço de ressignificações e descobertas, há no sentimento dos estudantes a preocupação com o presente e o futuro de sua formação acadêmica. Mesmo que a análise seja feita durante o período da pandemia, surge a preocupação dos estudantes quanto ao retorno a esse espaço de formação escolar, regressar presencial ou de forma remota ao CPII. A maioria dos estudantes manifesta sentir falta do colégio, da relação com os colegas e com os professores. A grande preocupação revelada por uma parte significativa dos estudantes, relativamente aos estudos, é que as aulas regressem apenas em 2021 e isso acarretar a perda do ano letivo. Cabe, então, indagar como ressignificar a relação da juventude com a escola durante e no pós-pandemia?

Os questionamentos colocados na fase inicial da pesquisa, a saber, Qual a visão que o jovem estudante do CPII possui sobre a sua vivência escolar? Qual a importância e significados que ele atribui à escola? Qual a importância que o jovem estudante do CPII atribui ao seu grupo de convívio escolar? Qual a sua capacidade de reagir à adversidade?, foram respondidos no decorrer da seção anterior. No entanto alguns novos questionamentos surgiram.

Problematizar, diante do cenário atual, a relação dos estudantes do CPII com a instituição, nos possibilitou compreender algumas contradições e oportunidades para enfrentar as batalhas que se seguirão ainda durante a pandemia e posteriormente quando gradativamente nos encontrarmos presencialmente nas escolas. 


\section{REFERÊNCIAS}

CASTELLS, Manuel. A Sociedade em rede São Paulo: Paz e Terra,1999.

CUNHA, Maria Antonieta Antunes. As melhores possibilidades da leitura na escola. Perspectiva, Florianópolis, v.17, n.31, p. 92, jan.jjun. 1999.

DAYRELL, J. (1996) . A escola como espaço sócio-cultural. Múltiplos olhares sobre educação e cultura. Belo Horizonte: UFMG, v. 194, p. 136-162

DAYRELL, Juarez. A escola como espaço sociocultural. In DAYRELL, Juarez. (org). Múltiplos olhares sobre educação e cultura. Belo Horizonte: Ed. UFMG, 2002. P. $136-161$

DAYRELL, Juarez . A escola "faz" as juventudes? Reflexões em torno da socialização juvenil . Educ. Soc. [conectados]. 2007, vol.28, n.100, pp.11051128. ISSN 1678-4626. https://doi.org/10.1590/S0101-73302007000300022 .

FREITAS, W. R. S.; JABBOUR, C. J. C. (2011), Utilizando Estudo de casos(s) como estratégia de pesquisa qualitativa: boas práticas e sugestões. ESTUDO \& DEBATE, Lajeado, v. 18, n. 2, p. 07-22, 2011

LIMA, Rogerio. Sociologia, interculturalidade e formação juvenil. Revista Coletiva. $\quad$ Recife: $\quad$ Número 172015.2 Link http://coletiva.labjor.unicamp.br/index.php/artigos/?n=493

OLIVEIRA, Luiz Fernandes de. A sociologia e as tensões sociais, epistemologias e culturais da escola. In OLIVEIRA, Luiz F. Pinto, Nalayane Mendonça. FIGUEIREDO, André Videira de. Sociologia na sala de aula: reflexões e experiências docentes no Estado do Rio de Janeiro: Rio de Janeiro: Imperial Novo Milênio, 2012. P. 89-108.

SACRISTÁN, J. G. A educação obrigatória: seu sentido educativo e social. Porto Alegre: Artmed. 2001.

SIMMEL, G. Simmel: Sociologia. Coleção Grandes Cientistas Sociais. São Paulo: Editora Ática, 1983 